\title{
SEISMIC RESPONSE OF HAGIA SOPHIA CHURCH IN THESSALONIKI INCLUDING SOIL-FOUNDATION-STRUCTURE INTERACTION
}

\author{
A. CHOUNTA ${ }^{1}$, C. MALAKOUdi ${ }^{2}$, C. PETRIDIS ${ }^{3}$ AND D. PITILAKIS ${ }^{4}$ \\ ${ }^{1}$ Civil engineer, Aristotle University of Thessaloniki \\ e-mail: nasiachounta@yahoo.gr \\ ${ }^{2}$ Civil engineer, Aristotle University of Thessaloniki \\ e-mail: malakoudichristina@gmail.com \\ ${ }^{3}$ Civil Engineer, $\mathrm{MSc}, \mathrm{PhD}$ Candidate, Aristotle University of Thessaloniki \\ e-mail: cpetridi@civil.auth.gr \\ ${ }^{4}$ Associate Professor, Aristotle University of Thessaloniki \\ e-mail: dpitilakis@,civil.auth.gr
}

Keywords: Historical Structure, Masonry, Monitoring, Non-Destructive Inspection

\begin{abstract}
This study investigates the behavior of "Hagia Sophia" church in Thessaloniki under seismic loading. It is one of the greatest Byzantine churches in the city and it is inscribed on the World Heritage List. The main scope of this work is to estimate the seismic response of the historic structure accounting for the actual foundation and soil flexibility at its base, to find the locations in need for retrofit and finally, to propose possible intervention methods. We simulate numerically the soil - foundation - structure system, and for the properties of the building materials we estimate their strengths with the use of two codes; the EC6 and the Greek Regulation for the structural intervention of masonry (KADET). We simulate soil-foundation flexibility using impedance functions under the foundation according to NIST (2012) provisions. The influence of soil-foundationstructure interaction is investigated. As a reference case, we also consider a fixed-base model to compare the output of the two analyses and highlight the influence of the soil and masonry foundation flexibility on the dynamic response of the church. Finally, we further analyze the intervention method of micropiles as a possible method of enhancement for the foundation of the monument.
\end{abstract}

\section{INTRODUCTION}

Hagia Sophia of Thessaloniki is one of the oldest Byzantine temples in the city of Thessaloniki, Greece [1]. Situated in the center of Thessaloniki, it still operates as the Cathedral of the City. It was built in the middle of the 7th century A.D., on the wreckage of a Christian basilica that was probably destroyed by an earthquake at the beginning of that century. During the 4th Crusade, in 1205, the building was used as a cathedral and during the Ottoman period, Hagia Sophia was converted into a mosque in 1430. It was reconverted to a church upon the liberation of Thessaloniki in 1912. Four years later, in 1917, the church suffered extensive damage due to the great fire and was gradually restored. The dome's restoration wasn't 
completed before 1980 [2].

In this paper, ETABS is used to model and analyze a 3D model of the church of Hagia Sophia accounting for the soil-structure interaction, using geotechnical data available from boreholes. Pitilakis and Karatzetzou (2015) concluded that SSI is important for heavy historical masonry structures [3] Two different types of springs are considered in order to compare the output of the two analyses and examine the importance of considering the influence of the soil and masonry foundation flexibility. The model is created in a simplified, yet accurate in terms of the dynamic characteristics, manner.

\section{DESCRIPTION OF THE STRUCTURE, BUILDING MATERIALS, AND SUBSURFACE OF THE CHURCH.}

Hagia Sophia is a heavy cubic building with internal dimensions $30.92 \mathrm{~m}$ width and $28.90 \mathrm{~m}$ length. To the east of the temple stands the chancel. In some parts of the temple, its foundations lay on arches, connected to the foundations of the pre-existing Christian basilica, on which it was built (9th Ephorate of Antiquities of Thessaloniki City, personal communication, 2018). The construction of the church is divided into 5 phases; 4 phases of the building and one of the later subsequent interventions (Fig. 1). The first three chronological phases are analyzed below, as they are present in the structural majority of the temple.
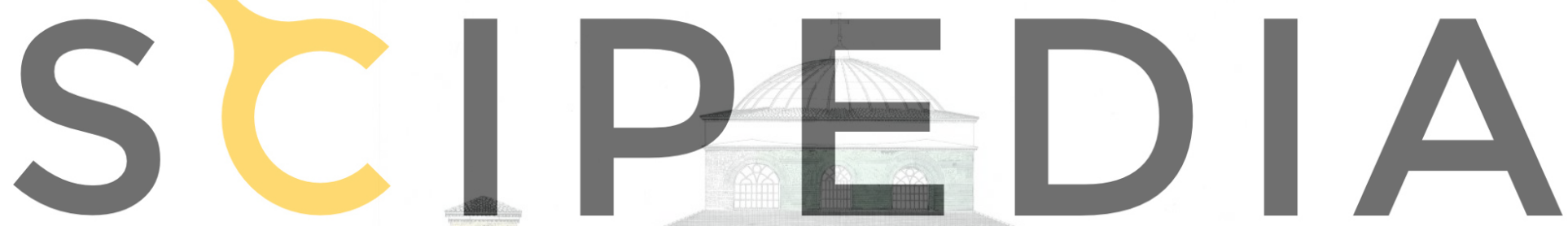

Register for free at https//www.scipedia.com to download the version without the watermark

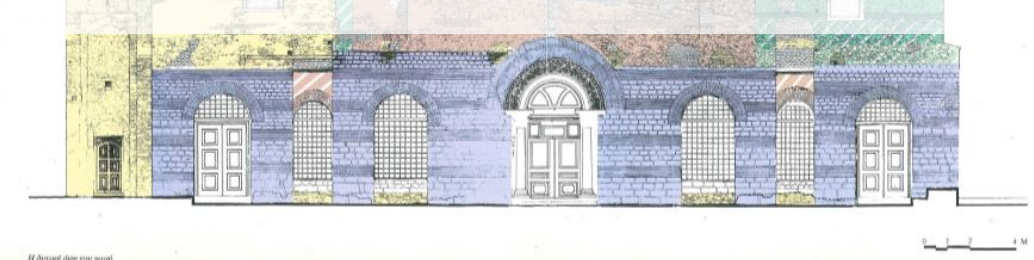

Figure 1: West view of "Hagia Sophia" church. [1]

Phase A: The foundations were made of stone known as gneiss, a green rock quarried from the surrounding hills. The masonry was composed of bricks and stones. The rough carving stones used were a mixture of limestone and sandstone in small proportion with a high content of shellfish fossils. This rock is not considered as a good building material because of its organic impurities. However, it's a material quite soft and easy to extract and carve. It is believed that it was imported from Chalkidiki, so it was a local material. This probably led to the use of this rock, despite its poor quality.

The bricks used were of good quality, with several aggregate impurities in the clay mass. 
Their dimensions were usually 40 -by-30 $\div 32-$ by $-4.5 \div 5 \mathrm{~cm}$. The mortar used for the construction is kurashani, a strong pink mortar. The use of crushed tile was also significant, both for the composition of cement in the form of brick powder and for the composition of aggregates, which exhibited continuous grading gradient, ranging in size from coarse sand to grains $1 \div 2$ $\mathrm{cm}$ in diameter.

Phase B: It is characterized by masonry that also forms brick and stone zones, but in this case, the red brick zones are less uniform. The stone used was schist and the building's mortar was similar to the first phase but sometimes less robust.

Phase C: The masonry consisted of irregular stones with joints filled with smaller stones and pieces of brick in horizontal layers. The exterior of the masonry had a rough appearance [1]. The following table shows the mechanical properties (modulus of elasticity E, specific weight $\gamma$, density $\rho$, Poisson's ratio $v$, strength of material $f_{b}$ and of mortar $f_{m}$ ) of the materials used in the temple (Table 1).

Following geotechnical research in the surrounding area of the temple, the following soil layers (Fig. 2) can be distinguished under the location of the temple [G.Penelis, personal communication, 2018].

From the results of the NSPT test and the Pitilakis et. al (1992) [4] equation, the velocity of shearwaves is ealculated from the relation: Vs $=132(\mathrm{~N} 60) \cdot 0.2271$ (N60 is the corrected value of $N$ ). Thus, the shear wave velocity for the first layer is $V_{\mathrm{s} 1}=231,91 \mathrm{~m} / \mathrm{s}$ for the second layer is $V_{\mathrm{s} 2}=274,98 \mathrm{~m} / \mathrm{s}$ and finally for the third layer is $V_{\mathrm{s} 3}=358,70 \mathrm{~m} / \mathrm{s}$. Finally, the mean $V_{\mathrm{s}}=280$ $\mathrm{m} / \mathrm{s}$ is obtained for the foundation soil. The shear modulus $\mathrm{G}$ is calculated from the equation

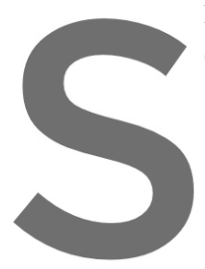
$\mathrm{G}=\rho \cdot \mathrm{V}_{\mathrm{s} 2}$
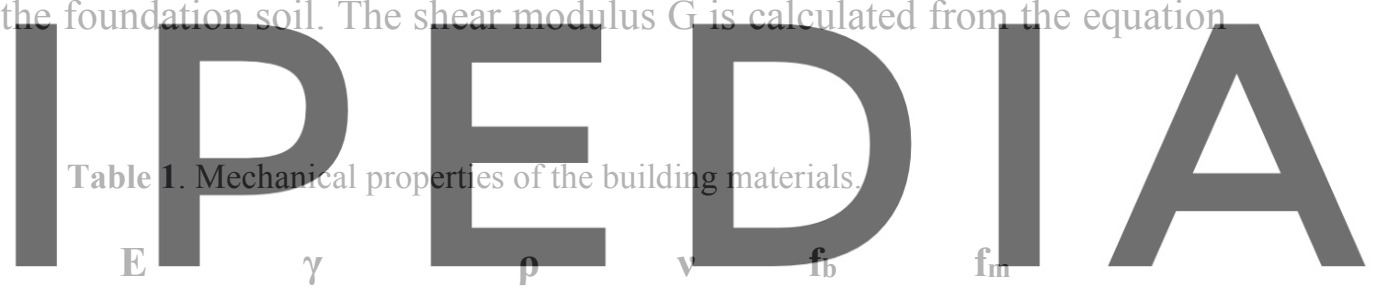

(Gpa) $\quad\left(\mathrm{KN} / \mathrm{m}^{3}\right) \quad\left(\mathrm{t} / \mathrm{m}^{3}\right) \quad(\%) \quad(\mathrm{Mpa}) \quad(\mathrm{Mpa})$

Register for free at https//www.scipedia.comotododownload the version without the watermark

\begin{tabular}{|c|c|c|c|c|c|c|}
\hline Gneiss & 30 & 27 & 2,25 & 15 & 40 & \\
\hline Kurashani & 5 & & 1,5 & 30 & & 2 \\
\hline \multicolumn{7}{|c|}{ Masonry - Phase A } \\
\hline Limestone & 30 & $\begin{array}{r}18.7 \div \\
26.9 \\
\end{array}$ & 1,8 & 15 & 40 & \\
\hline Sandstone & 20 & $\begin{array}{c}22.0 \div \\
27.0\end{array}$ & & & 30 & \\
\hline Brick & & 20 & 1,5 & 16 & 40 & \\
\hline Kurashani & 5 & & & & & 2 \\
\hline \multicolumn{7}{|c|}{ Masonry - Phase B } \\
\hline Schist & 50 & 28 & & 20 & 60 & \\
\hline Brick & 40 & 20 & 1,5 & 16 & 30 & \\
\hline Kurashani & 5 & & & & & 2 \\
\hline \multicolumn{7}{|c|}{ Internal column } \\
\hline Marble & 80 & $\begin{array}{r}26.4 \div \\
28.6 \\
\end{array}$ & 2,7 & 20 & 80 & \\
\hline
\end{tabular}




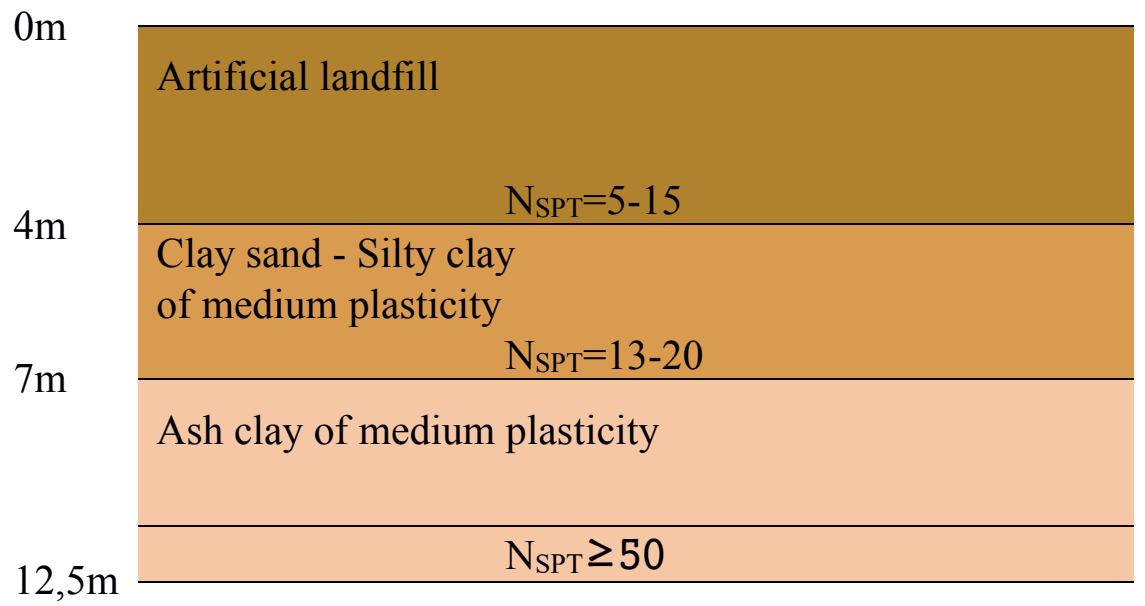

Figure 2. Territorial section of the subsurface, from the surrounding area of the temple. (Nspt is the value of standard penetration resistance)

\section{3D NUMERICAL MODELING OF THE TEMPLE}

The strengths of the building materials were impaired with the use of the Greek Regulation of the structural intervention of masonry (KADET) [5]. The purpose of the Regulation is to establish criteria for a

formed by mortar-bonded stontes repairs or reinforcements.

Its purpose is to:

1. Provide criteria for evaluating the seismic behavior of

2. Describe the approach for selecting the necessary corrective measures.
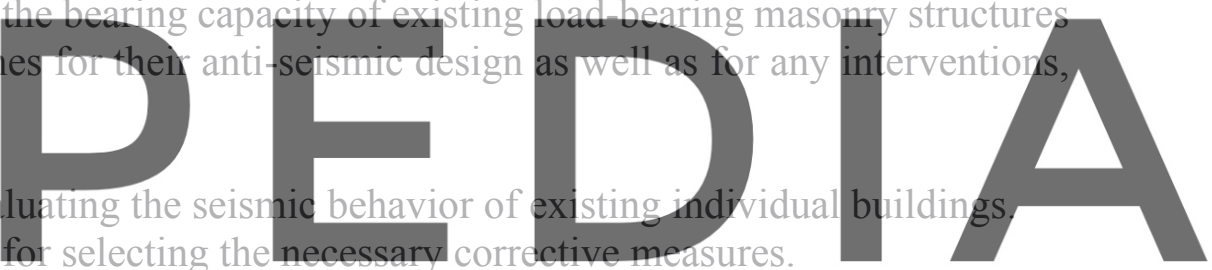

3. Set criteria for the design of intervention measures

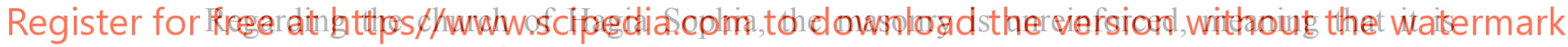
composed exclusively of stones and mortar. It's also a three-layer masonry (see Fig. 3), which means that there is a gap area between the two outer walls of the masonry consisting of filler material. The filler consists of pieces of stone and/or mortar mixed with mortar (usually the same as construction mortar) and spaced at intervals in height, without condensation. Thus, it is usually a relatively loose material with a large percentage of gaps and very poor mechanical properties.

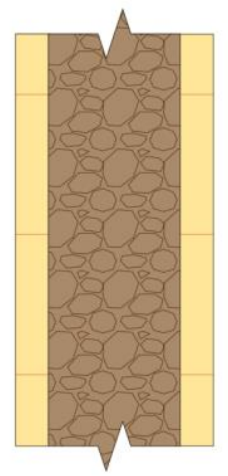

Figure 3. Sketch of the three-layer masonry. 
The compressive strength of three-layer masonry can be estimated by the following relation:

$$
f_{W C}=\frac{1}{\gamma R d} \frac{2 \lambda_{e} \delta f_{c, e}+\lambda_{i} f_{c, i}}{1+2 \delta}
$$

where, $\delta$, is the ratio of the thickness of the outer side to the thickness of the filler, $\mathrm{f}_{\mathrm{c}}, \mathrm{e}$, and $\mathrm{f}_{\mathrm{c}}$, are the compressive strength of the outer walls and the filler respectively, $\lambda_{\mathrm{e}}(<1,00)$ and $\lambda_{\mathrm{i}}(>$ $1,00)$ are empirical coefficients, which take into consideration the interaction of outer layers and filler material, $\gamma_{\mathrm{Rd}}$, is an uncertainty index, which can be taken equal to 1.50 . The uncertainty ratio is taken as 1.25 . The compressive strength of the filler is obtained equal to the $2 / 3$ of the compressive strength of the outer walls [C. Ignatakis, personal communication, 2018].

The characteristic compressive strength of three-walled masonry is calculated by the equation: $\mathrm{f}_{\mathrm{Wc}}{ }^{k}=f_{\mathrm{Wc}}-1,645$, and the specific modulus is 1000 times the characteristic compressive strength of each wall. Finally, the introduced specific modulus in the program is equal to half of the calculated (loss of material strength due to the age of construction) [5].

The table below (Table 2) shows the calculation that led to the values of comprehensive strength $f_{\mathrm{wc}}$ and modulus of elasticity $\mathrm{E}_{\mathrm{wc}}$ of the masonry, which were input into the program. The parameters shown on the equations are the following: $f_{b c}$ and $f_{m c}$ the compressive strength of lithosomes and mortar respectively, $\gamma_{\mathrm{Rd}}$ an uncertainty index, outer wall $\mathrm{f}_{\mathrm{c}, \mathrm{e}}$ and filler material $\mathrm{f}_{\mathrm{ci}}$ comprehensive strength, the empirical factor ${ }^{\xi}$ which takes into account the adverse effect of the mortar joints' thickn layers and filler materi filler and coefficient The first model exan a model fixed in the entire height and length of
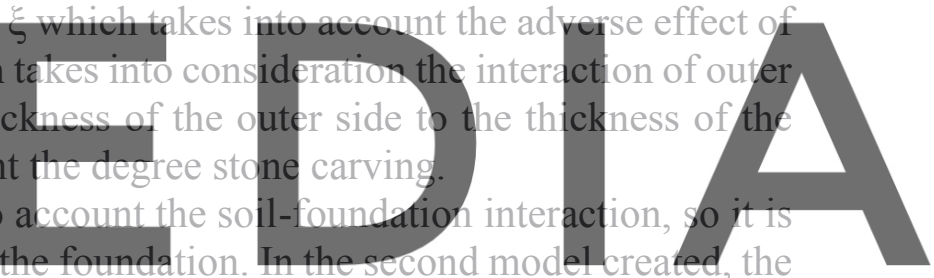

foundation substrate was simulated by vertical and horizontal springs applied around the length

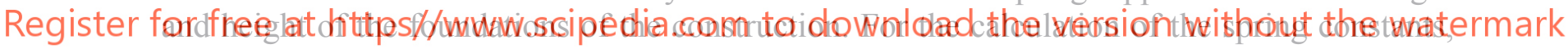
the properties of the soil under the foundation were used.

The soil-foundation flexibility was simulated using impedance functions under the foundation, according to NIST 2012 provisions [6]. The term "soil-structure interaction" describes the differentiation in the dynamic response of construction when taking into account the finite stiffness of the foundation and the underlying soil. More specifically there is:

- Modified movement at the base of the construction.

- Different dynamic oscillation characteristics of the building due to foundation flexibility.

- The oscillation of the structure imposes additional stresses and deformations on the base resulting in increased damping of the system.

The model was made by making some simplifying assumptions. The assumptions and simplifications lead to a rougher description of the church, however reliable enough to exclude significant errors in its analysis. These assumptions were:

1. Not modeling the dome, whose loads were calculated and imposed on the perimeter walls of the temple. 
2. Not modeling the upper floor whose impact is simulated by a diaphragm.

3. The curved surfaces of some elements, e.g. of the three-sided chancel and the arched openings, were simulated with polygonal surfaces.

4. Ignoring the arched connection of the foundations of Hagia Sophia with foundations of earlier periods.

5. Due to the large volume of the monument and its corresponding weight, the live loads are considered negligible and are not taken into account in the solution.

6. Due to the similar mechanical characteristics of the masonry materials in the first and second phase, it is assumed that the masonry up to the height of the masonry belongs to one phase.

7. Firstly, five masonry sections were created, with different dimensions each one, to simulate different thicknesses in each side of the temple and one frame section for the simulation of the marble columns.

8. The model was created in 3 stages, first the foundation, after the first level until the height of the upper room, and finally the second level until the height of the roof. Thereafter, the model was discretized (meshed), in every $0,5 \mathrm{~m}$, and all the openings have been designed (Fig.4). The influence of the upper room and the dome was simulated by the entrance of two diaphragms, one at the end of the first and one at the end of the second level, respectively.

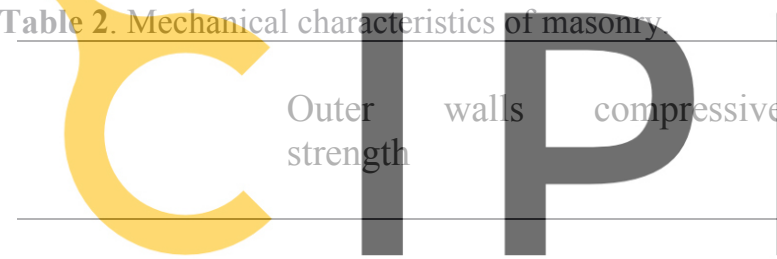

$\mathrm{f}_{\mathrm{wc}}=\xi \cdot\left[\left\{\frac{2}{3} \mathrm{f}_{\mathrm{bc}}{ }^{0,5}-\mathrm{f}_{\mathrm{o}}\right\}+\lambda \cdot \mathrm{fmc}_{\mathrm{mc}}\right](\mathrm{Mpa})$

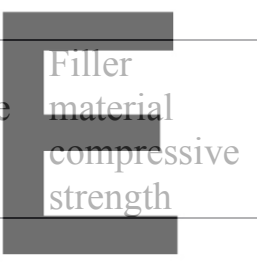

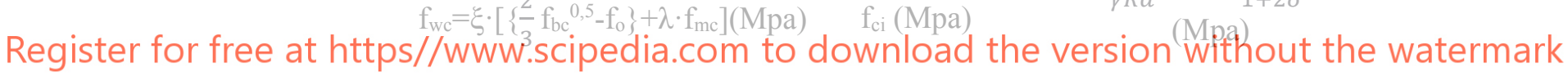

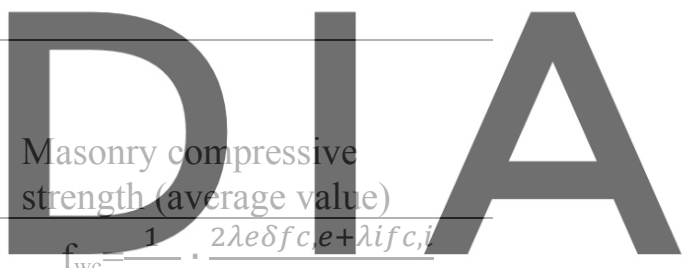

$1+2 \delta$

\begin{tabular}{llcc}
\hline Foundation & 2,966370214 & 1,98 & 1,90 \\
\hline Masonry A,B & 2,694053189 & 1,80 & 1,72 \\
\hline Masonry C & 1,73142397 & 1,15 & 1,11 \\
\hline & Masonry compressive strength & $\begin{array}{c}\text { Modulus } \\
(\mathrm{EC} 6)\end{array}$ & Modulus (final) \\
\hline & $0,67 \cdot \mathrm{f}_{\mathrm{wc}}(\mathrm{Mpa})$ & $\mathrm{E}_{\mathrm{wc}}=1000 \cdot \mathrm{f}_{\mathrm{wc}}(\mathrm{Mpa})$ & $\mathrm{E}_{\mathrm{wc}}{ }^{\prime}=1 / 2 \cdot \mathrm{E}_{\mathrm{wc}}(\mathrm{Mpa})$ \\
\hline Foundation & 1,27 & 1271,98 & 635,99 \\
\hline Masonry A,B & 1,16 & 1155,21 & 577,61 \\
\hline Masonry C & 0,74 & 742,43 & 371,22 \\
\hline
\end{tabular}



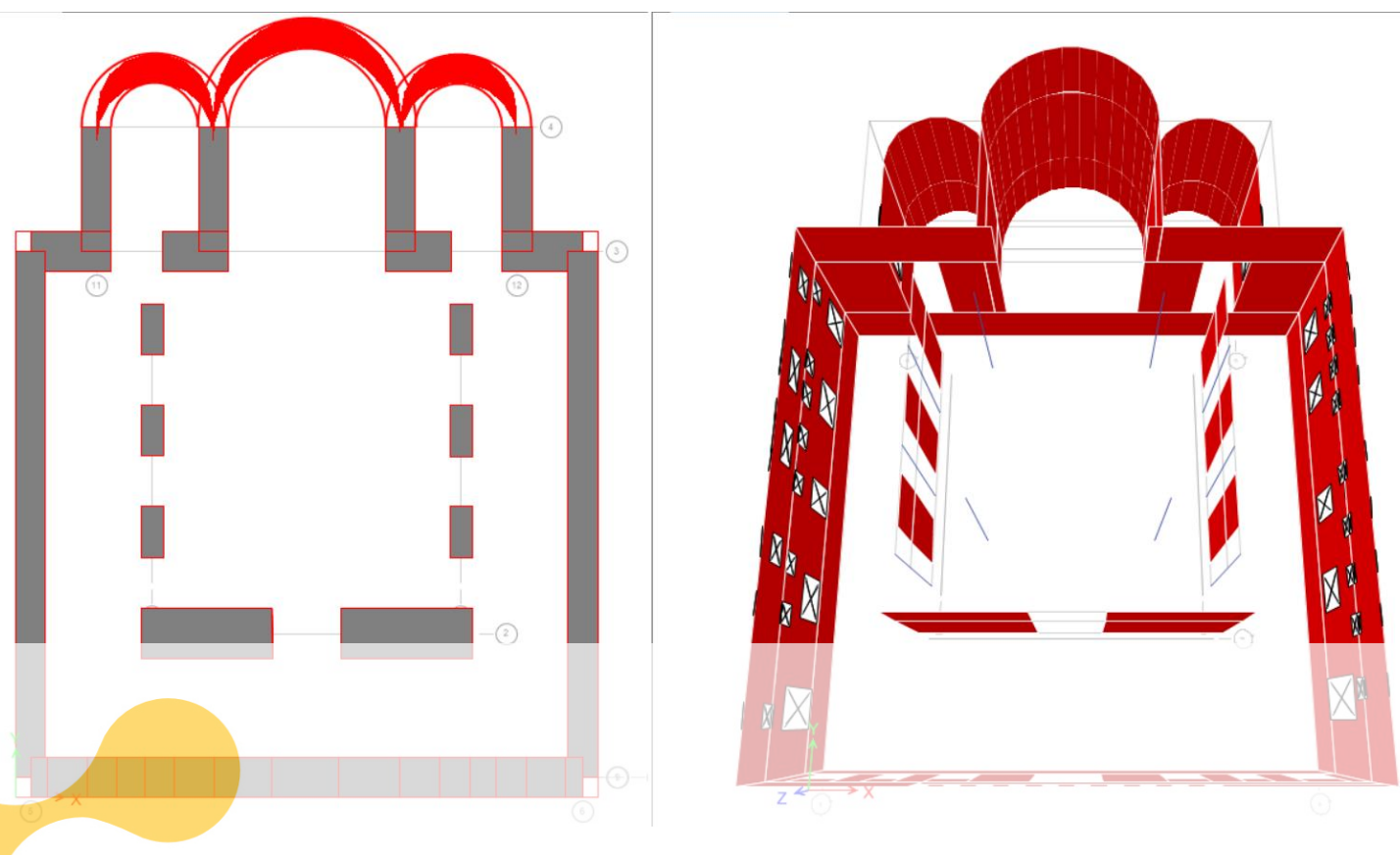

Figure 4. Plan view of the ground floor and 3D model design before the change of the three-sided chancel into polygonal surfaces.
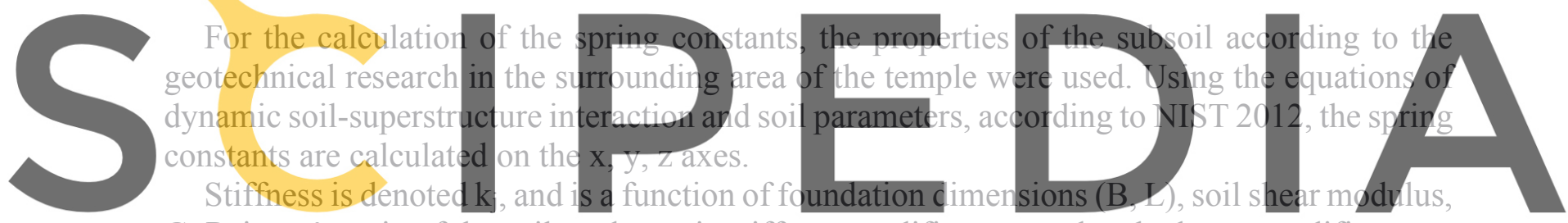

G, Poisson's ratio of the soil, v, dynamic stiffness modifiers, aj, and embedment modifiers, $\eta_{j}$.

Register for free at https//www.scipedia.com to download the version without the watermark

, where $\mathrm{K}_{\mathrm{j}}$ is the static foundation stiffness at zero frequency for mode $\mathrm{j}$. The equations used for the calculations of the spring's components are presented on the following Table (Table 3). [4]

The behavior of the soil has been simulated by modeling the same with a set of linear elastic springs. Three translational springs along mutually perpendicular global axes are assigned to all the nodes that are perpendicularly along the length and height of the foundations of the structure. Indicatively on the foundation of the south wall, the stiffness calculated respectively for $\mathrm{z}$ direction, $\mathrm{y}$ direction and $\mathrm{x}$ direction were $\mathrm{k}_{\mathrm{z}}=11228225 \mathrm{~N} / \mathrm{m}, \mathrm{k}_{\mathrm{y}}=12226456 \mathrm{~N} / \mathrm{m}$ and $\mathrm{k}_{\mathrm{x}}=9796668 \mathrm{~N} / \mathrm{m}$. These values were divided by the nodes corresponding to each direction and applied to the model as linear elastic springs. The same procedure was followed for all parts of the church foundations. In addition, a fixed-base model was created to compare the results of the two analyzes in order to better understand the effect of the soil on the dynamic response of the model. 
Table 3. Pais and Kausel (1988) [7] equations, used for the calculations of the foundation springs

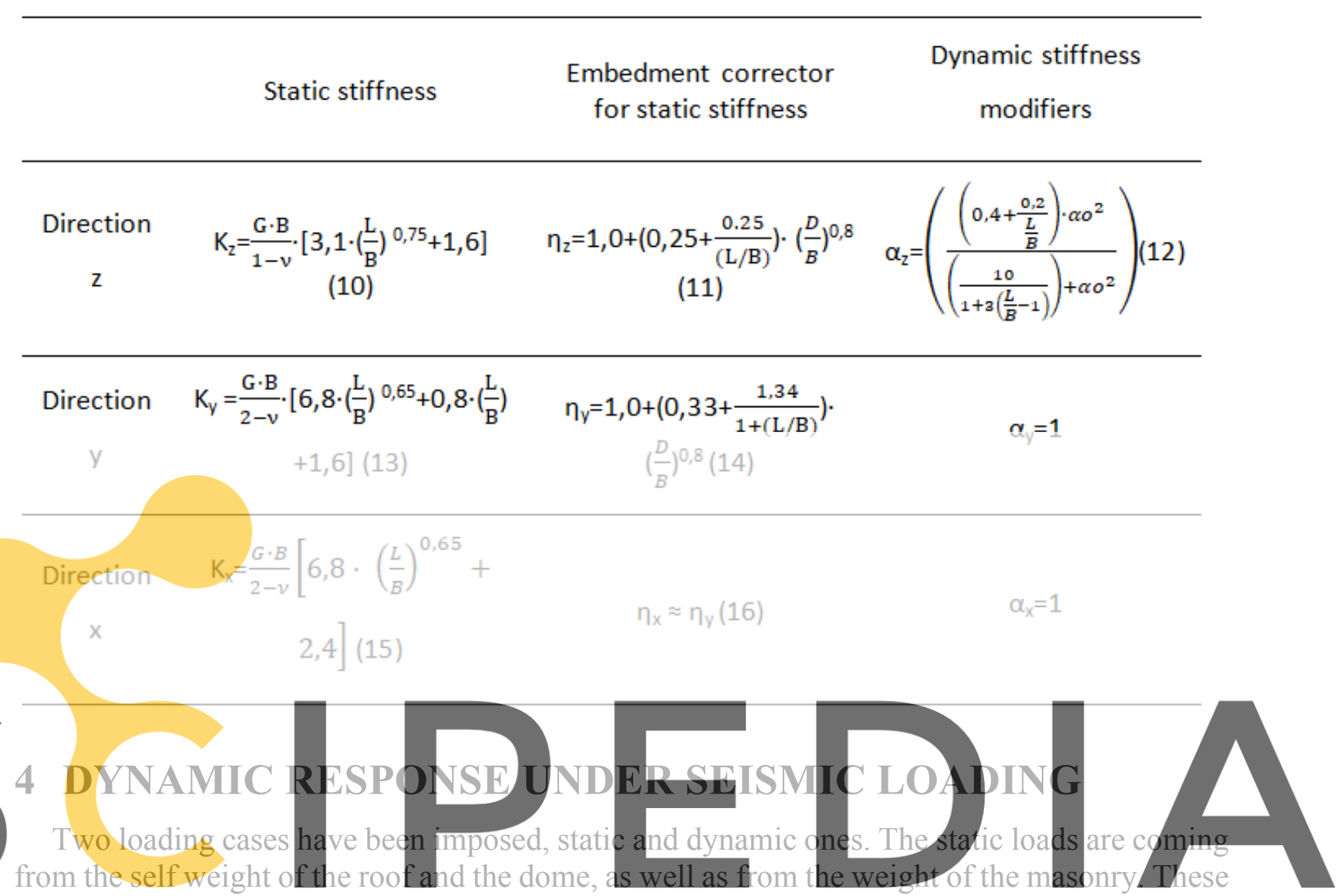

loads have been calculated and applied to the perimeter of the masonry, as vertical forces. The

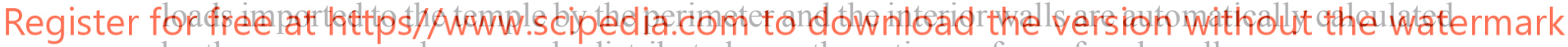
by the program and are evenly distributed over the entire surface of each wall.

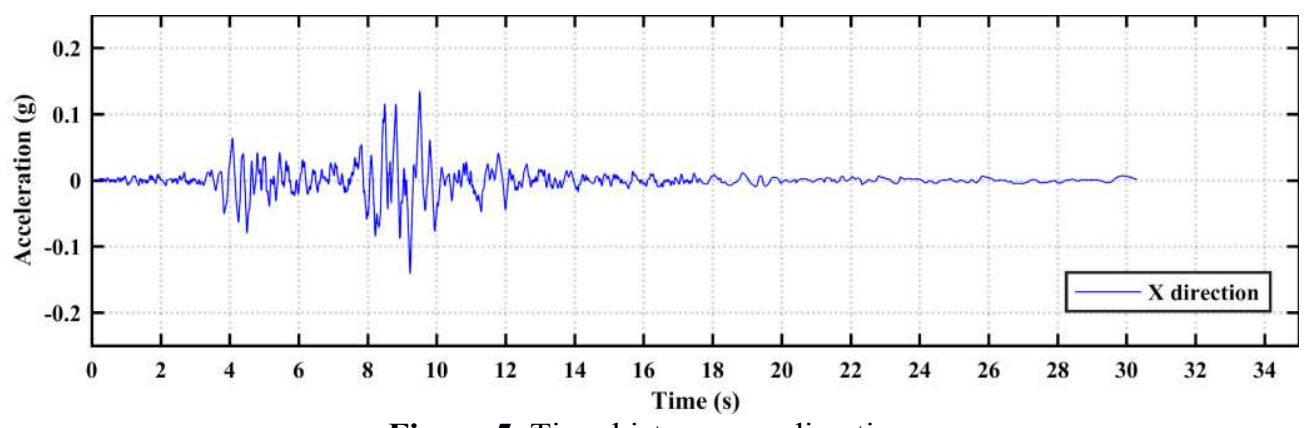

Figure 5. Time history on $\mathrm{x}$ direction 


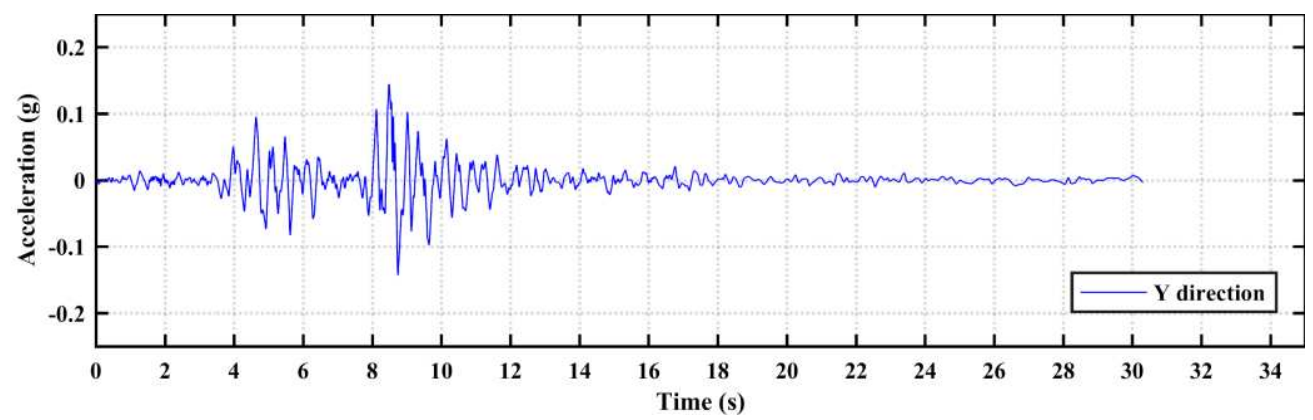

Figure 6. Time history on y direction

Model dynamic loading: The analysis is carried out first for the charge status of the self weights, as the mobile loads are ignored, and then the seismic action is added. The simulation of the seismic activity was carried out by the introduction of accelerometers recorded during the Thessaloniki earthquake on June 20,1978 at the CITY Hotel. It is chosen to simulate the seismic motion in terms of time-acceleration time histories. The following figures illustrate the time histories of the charge states in the x (Fig.5) and y (Fig.6) directions. A time step of 0.01s resolutions is set and 3000 consecutive steps are selected in total.

The results of the seismic response of the model are presented through diagrams of maximum movements, at non-simultaneous times. Therefore, the distribution of the growing stresses of the south wall of the temple are presented.

The maximum displacements at non-simultaneous moments, in the fixed-base model (Fis 7) and in the model with following figure. The horit the vertical is the height of the construction at displacements are zero, model, small-value di p h salable soil (fig. 7), under setsmic
of the contal axis shoys the value of the disp
of throughout the foundation while on the displacements are increasing as we approach the height of the first floor and after decreasing Register forifiede at https//www.scipedia.com to download the version without the watermark

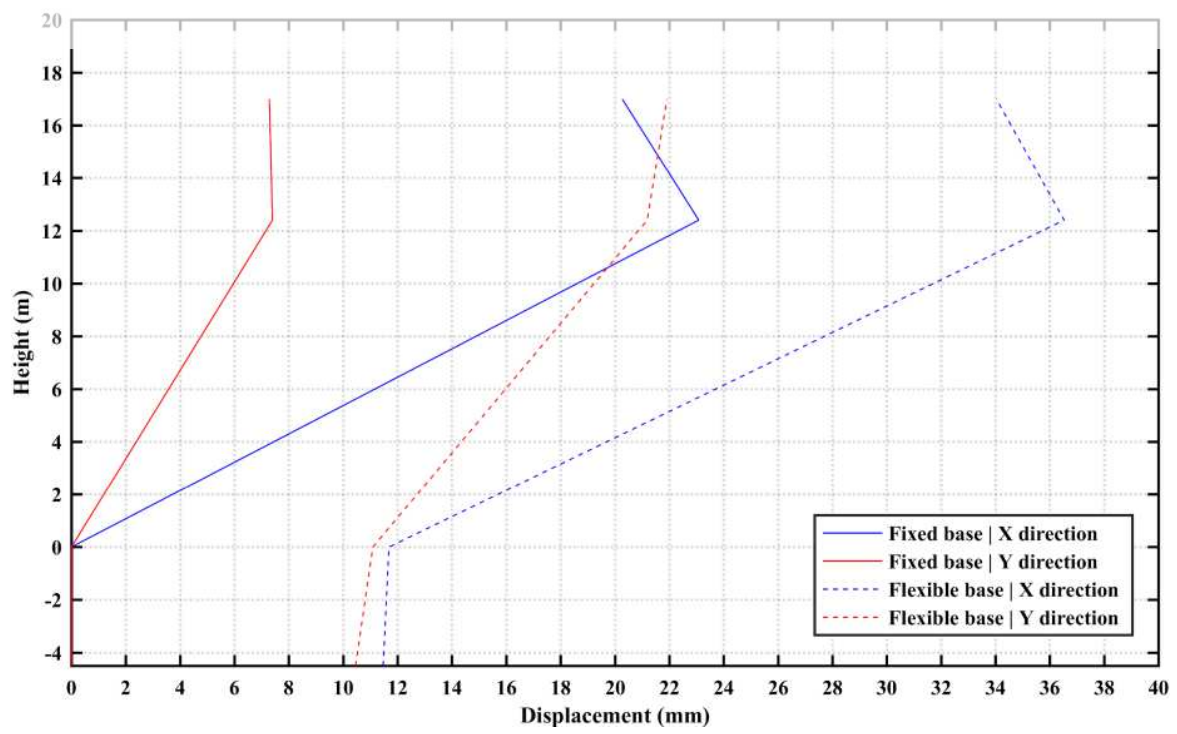

Figure 7. Displacements on fixed and on the flexible base model. 


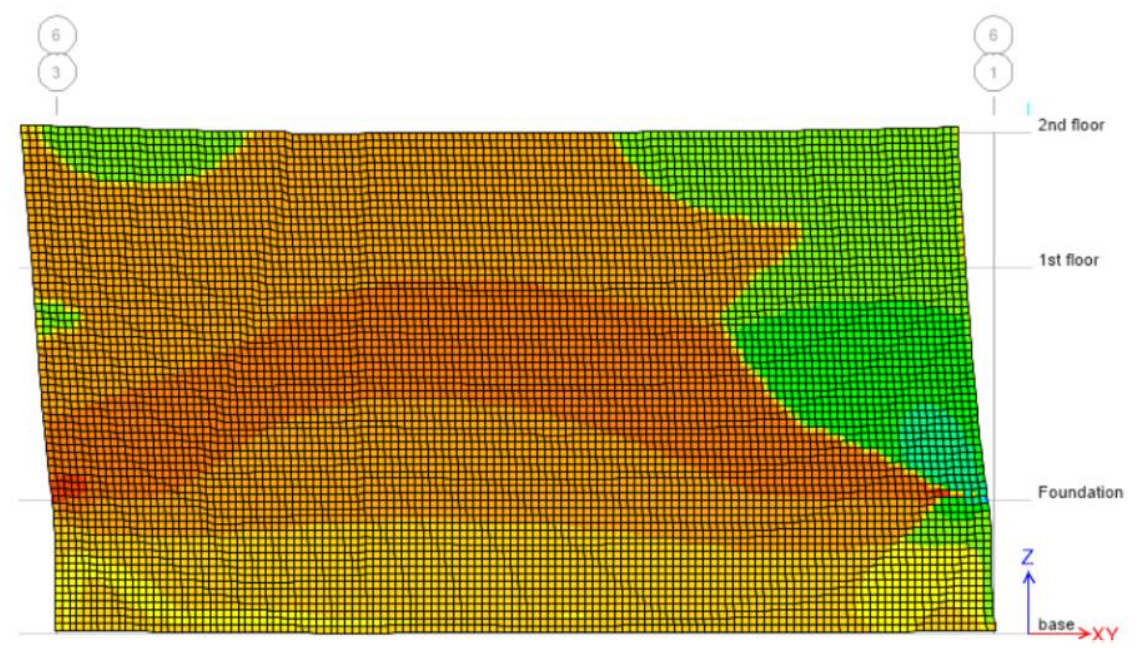

Figure 8. Distribution of shear stresses on the south wall of the temple. (model with springs) The horizontal axis at the bottom of the figures shows quantitative (color-based) stresses in the temple in MPa.

Figure 8 shows the distributed shear stresses at non-simultaneous times on the south wall of the temple as recorded in the ETABS program. The horizontal axis at the bottom of the image shows quantitative (color-based) stresses in the wall in MPa. On the south wall, negative

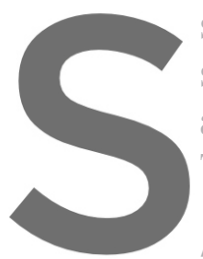
stresses (orange) are dos stresses (green) are deve adjacent walls, which art This indicates a greater 5 REHABILITATION METHOD
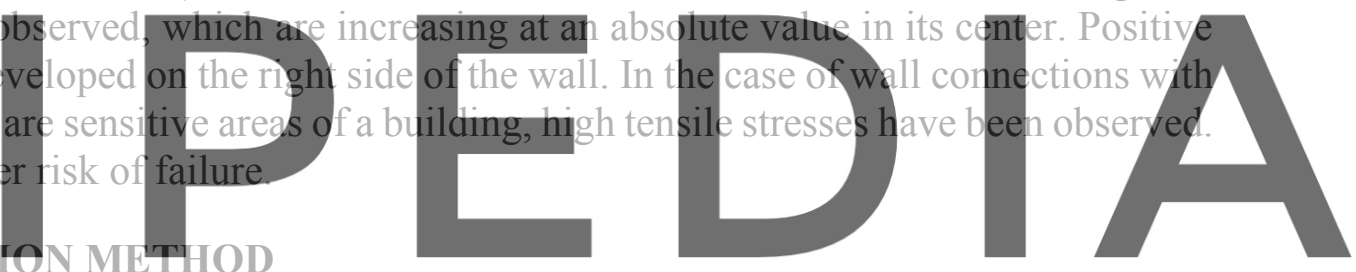

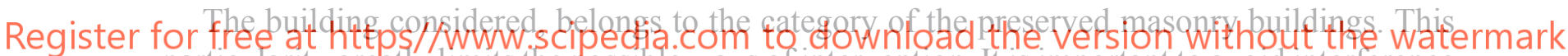
particularity greatly limits the possible ways of intervention. It is important to avoid interference

on the frame of the church. The main purpose is the measure to be as painless as possible, to not damage the cultural heritage. The proposed method is deep subjection using micropiles. This technique is designed to succeed in both soil and bearing capacity of foundations improvement. Micropiles have a quick application, and they can gradually receive loads and lead to the stabilization of the displacements. For a succeeding application of the technique, the cost might be relatively high.

In order to simulate the micropiles in the model, the values of the spring constants were increased. This is achieved by increasing $\mathrm{G}$ by $50 \%$. Thus, the spring constants resulting from this modification indicative for the south wall, that was previously analyzed, were $\mathrm{Kz}=$ $16842338 \mathrm{~N} / \mathrm{m}, \mathrm{Ky}=18339684 \mathrm{~N} / \mathrm{m}$ and $\mathrm{Kx}=14695002 \mathrm{~N} / \mathrm{m}$. These spring values were then applied to the model in the same way as discussed above. The results of displacements in relation to displacements with non-reinforced springs are shown in Fig. 10.

From the results of the analysis of the model after reinforcement, there is an increase in the stiffness of the construction and decrease on the displacements, a 5\% decrease in the x direction and a $30 \%$ decrease in the y direction, compared to the original spring model. Therefore, it seems that micropiles could be a valuable solution to the reinforcement of the foundation. 


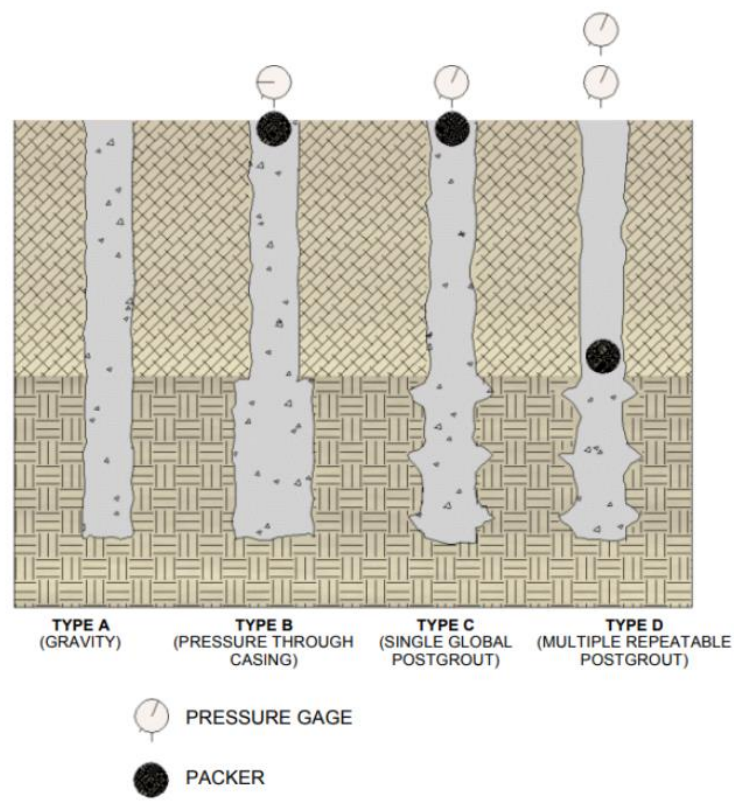

Figure 9. Type of micropiles used in practice, according to [8] .

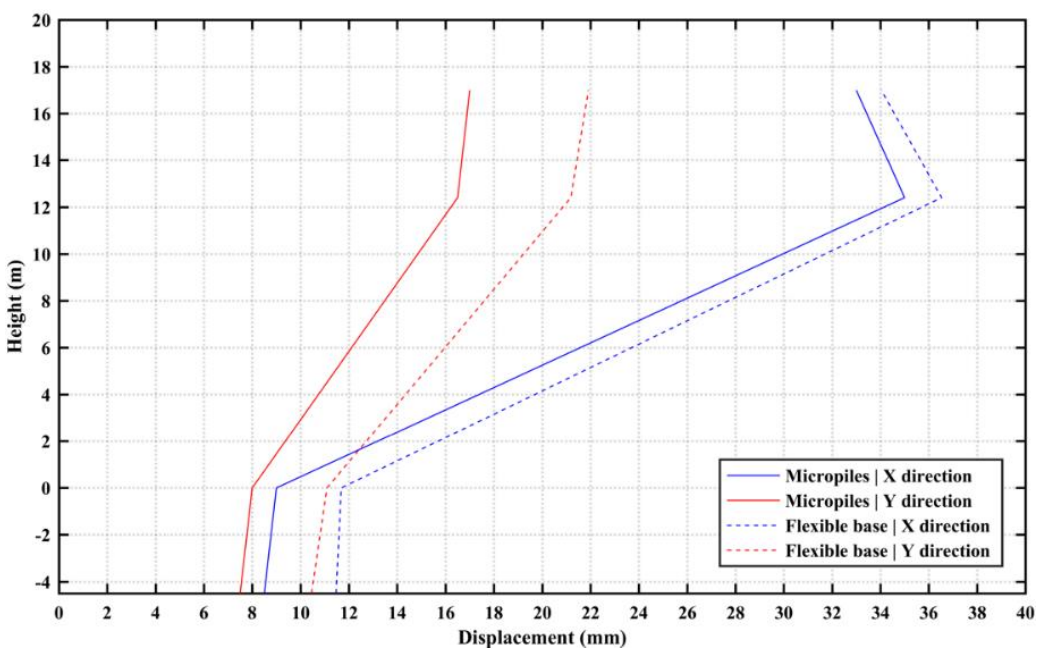

Figure 10. Displacements on the flexible base model and on model with micropiles.

\section{CONCLUSION}

Comparing the two models (fixed base model and model with no reinforcement springs), there is an increase in the idle period as well as an increase in the total and relative drift of the construction to the model with the springs relative to the fixed model. The maximum displacement does not occur at any of the corners of each wall. For the spring model, it is 35.9 $\mathrm{mm}$ in $\mathrm{x}$-direction and $21.1 \mathrm{~mm}$ in y-direction, while for the spring model it is $22.3 \mathrm{~mm}$ and $8.0 \mathrm{~mm}$ in the $\mathrm{x}$ - and $\mathrm{y}$-directions respectively. The maximum off-plane movements are observed in the middle of each wall and this is because there is their free section (we have offplane commitments at the endpoints of the wall). It is therefore observed that due to the 
introduction of the springs the translations at the checkpoints are increased by $60 \%$ in the $\mathrm{x}$ direction and $175 \%$ in the y-direction.

As shown in the workflow and results of the work, the influence of the dynamic soilsuperstructure interaction plays an important role in the construction response, so a proper foundation simulation cannot be based on a flexibility-ignorant model. It is necessary to consider the soil-structure interaction in assessing the vulnerability of heavy structures and in managing seismic risk. Finally, an important conclusion is that the reliability of the results is largely based on assumptions and simplifications made by the user during modeling. Thus, experience and knowledge of the behavior of the construction against past earthquake events play a crucial role.

In cases where monuments renovation, in which an intervention is to be performed, its effectiveness should be studied in detail. As shown in the results after the simulation of the micropiles the decrease of the displacements were not as large as those of the model with the non-reinforced springs, so it would be incorrect to rely on this study for possible intervention, given the high cost of their construction. The present paper uses linear analysis as a reliable method to evaluate the effectiveness of various building reinforcement interventions before they are implemented. However, nonlinear analysis could be a more accurate method.

\section{ACKNOWLEDGMENTS}

We acknowledge support by the project "HELPOS - Hellenic Plate Observing System" (MIS 5002697) which is implemented under the Action "Reinforcement of the Research and Innovation Infrastructure", funded by the Operational Programme "Competitiveness, Entrepreneurship and Innovation" (NSRF 2014-2020) and co-financed by Greece and the European Union (European Regional Development Fund).

\section{REFERENCES}

[1] Theocharidou K. The architecture of Hagia Sophia, Thessaloniki. Publish of The Archaeological Receipts and Expropriations Fund, (1994).

[2] Hagia Sophia, Thessaloniki. Wikipedia, viewed 15 July 2019.

[3] Pitilakis D., Karatzetzou A. Dynamic stiffness of monumental flexible masonry foundations. Bulletin of Earthquake Engineering. 13(1):67-82 (2015).

[4] Pitilakis K., Anastasiadis A. and Raptakis D. Field and laboratory determination of dynamic properties of natural soil deposits. Proceedings of the10th world conference on earthquake engineering, (1992).

[5] Greek Regulation of the structural intervention of masonry (KADET). (1 ${ }^{\text {rst }}$ plan 2019), Athens, (2019).

[6] NIST, 2012. Soil-Structure Interaction for Building Structures. Tech. Rep. (2019).

[7] Pais, A. and Kausel, E. Approximate formulas for dynamic stiffnesses of rigid foundations. Soil Dynamics and Earthquake Engineering (1988) 7(4): 213-227.

[8] Antunes, T. Rehabilitation of foundation of old buildings using micropiles. (extended abstract). Técnico Lisboa, Lisbon, Portugal, (2012). 